\title{
Research Advances of Leptotrombidium scutellare in China
}

\author{
Rong Xiang, Xian-Guo Guo* (i) \\ Vector Laboratory, Institute of Pathogens and Vectors, Yunnan Provincial Key Laboratory for Zoonosis Control and Prevention, Dali University, Dali, \\ Yunnan Province 671000, China
}

\begin{abstract}
Leptotrombidium scutellare is one of the 6 main vectors of scrub typhus in China. It has been found in more than 15 provinces of China. Especially in Yunnan, it was found to be mainly distributed in some mountainous areas with high altitude, low temperature and low precipitation. Rodents and some other small mammals were the most common hosts of $L$. scutellare. To date, more than 40 host species of $L$. scutellare have been recorded with very low host specificity, and the main hosts varied in different geographical regions. L. scutellare had a strong resistance against the cold environment, and the temperature and humidity were 2 important factors affecting its growth and development. Among different individuals of their rodent hosts, $L$. scutellare mites often showed an aggregated distribution pattern, which reflected the interspecific cooperation of the mites. The chromosome karyotype of $L$. scutellare was $2 n=16$ and all the 8 pairs of chromosomes were short rod-shaped with metacentric or sub-metacentric types. The isozyme spectrum supported that L. scutellare, L. deliense and L. rubellum were in the same species group. Based on the natural infection, experimental transmission and epidemiological evidence, $L$. scutellare has been eventually confirmed as the second major vector of scrub typhus in China, which is second only to L. deliense.
\end{abstract}

Key words: Leptotrombidium scutellare, chigger mite, vector, scrub typhus, review

\section{INTRODUCTION}

Chigger mites are a large group of arthropods and they are also known as chiggers, trombiculid mites, tsutsugamushi mites, sand mites, grass itch mites, scrub itch mites and harvest mites [1-3]. There have been about 3,000 species recorded throughout the world, about 60 species of them can effectively transmit scrub typhus $[1,4]$. Some species of chigger mites are the effective transmitting vector of scrub typhus (tsutsugamushi disease) caused by the causative agent Orientia tsutsugamushi. Associated with rodents and some other small mammals, scrub typhus is a natural epidemic disease (zoonosis) [5,6], and it is widely distributed in the Asia-Pacific region, including China, South Korea, Japan, India, Pakistan, Thailand, Sri Lanka, Philippine, Indonesia, southwest Pacific Islands and Australia $[1,2,4]$. Of more than 500 species documented in China $[1,7]$, there are 6 main vectors of scrub typhus, namely Leptotrombidium deliense (Walch, 1922), L. scutellare (Nagayo et al., 1921), L. rubellum (Wang and Liao, 1984), L. sialkotense (Ver-

\footnotetext{
- Received 21 August 2020, revised 15 December 2020, accepted 27 December 2020.

*Corresponding author (xianguoguo@yahoo.com)

(C) 2021, Korean Society for Parasitology and Tropical Medicine

This is an Open Access article distributed under the terms of the Creative Commons Attribution Non-Commercial License (https://creativecommons.org/licenses/by-nc/4.0) which permits unrestricted non-commercial use, distribution, and reproduction in any medium, provided the original work is properly cited.
}

cammen-Grandjean \& Langston, 1976), L. wenense (Wu et al., 1982) and L. insulare (Li, Wang \& Chen, 1997) [1,2]. L. sialkotense and $L$. wenense were previously called $L$. jishoum Wen et al., 1988 and $L$. kaohuense Li et al., 1997 respectively. Now $L$. jishoum has been proved to be the synonym of $L$. sialkotense and $L$. kaohuense the synonym of $L$. wenense $[1,8]$.

As one of dominant species of chigger mites in China, $L$. scutellare is very important in the transmission of scrub typhus because it is widely distributed in many parts of China. Of the 6 main vectors of scrub typhus in China, L. scutellare is the second major vector of scrub typhus and its medical significance is next only to $L$. deliense, the first major vector of scrub typhus in China $[1,2,9]$. Besides transmitting scrub typhus, L. scutellare is also suspected to potentially transmit hemorrhagic fever with renal syndrome (HFRS), which also known as epidemic hemorrhagic fever (EHF) in China [10,11]. Caused by Hantavirus, HFRS is also a zoonosis associated with rodents and some other small mammals [12,13].

\section{DISCOVERY, MORPHOLOGY AND IDENTIFICATION}

L. scutellare was the first found on the vole Microtus montebelli (Milne-Edwards) in Yamagata prefecture of Japan, and its original scientific name was Trombicula scutellaris named by Miyagawa Nagayo, Mitamura, Tamiya and Tenjin in 1921 [14]. 
In 1997, it was revised to Leptotrombidium (Leptotrombidium) scutellare by Chinese scientists (Li, Wang \& Chen, 1997) [8]. Now its accepted name has been changed to L. scutellare (Nagayo et al., 1921) $[1,8]$.

Like other species of chigger mites, the identification of Leptotrombidium scutellare is based on the morphology of the larvae $[1,8]$. The abbreviations for the morphological structure of the larval mite were showed in Table S1. The following morphological characteristics are the key points for identifying $L$. scutellare (the larval stage): orange or bright red; short and wide body without waist indentation; 238-377 ( $\mu \mathrm{m}$ ) of body length and 137-288 $(\mu \mathrm{m})$ of body width; approximately rectangular scutum with a convex posterior margin, and a concaved anterior and lateral margin; $\mathrm{PW} / \mathrm{SD}=1.64 ; 5$ pinnate setae on the scutum (including $1 \mathrm{AM}, 2 \mathrm{AL}$, and $2 \mathrm{PL}$ ); the naked base of 2 sensilla but 7-8 pairs of slender branches at the distal ends; $\mathrm{fPp}=\mathrm{N} / \mathrm{N} / \mathrm{BNN}$; $\mathrm{Pc}=3 ; \mathrm{Gn}=2 ; \mathrm{fSc}: \mathrm{PL}>\mathrm{AM}>\mathrm{AL} ; \mathrm{SB}-\mathrm{PL}$ (2 PL on the same horizontal line with 2 sensilla); $\mathrm{fCX}=1.1 .1$; $\mathrm{fSt}=2.2 ; \mathrm{fDS}=2 \mathrm{H}-10-[10-2]-[12-4]-8-6-2 ; \mathrm{DS}=56 ; \mathrm{VS}=38$; $\mathrm{NDV}=94 ; \mathrm{Ip}=858$; AW71-72, PW 79-82, SB 30-32, ASB 2932, PSB 15-17, SD 44-49, AP 28-29, AM 57-59, AL 50-51, PL 62-64, S78-86, H 62, $D_{\min } 44, D_{\max } 57-69, V_{\min } 34, V_{\max }$ 50, pa 295, pm 256, pp 307 (Fig. 1) [1,8]. Since the 6 main vectors of scrub typhus in China belong to the same genus, Leptotrombidium, it is necessary to differentiate L. scutellare from the other 5 vector species in practice. Table 1 summarized the key points of identifying the 6 main vectors of chigger mites $[1,2,8,9]$.

Early in 1956, a Chinese scientist (Chen) once named a subspecies of Leptotrombidium scutellare, L. scutellare basoglabrose (Chen et al. 1956), which was collected from the body surface of the rat Rattus losea (Swinhoe, 1870) [1]. The subsequent study, however, showed that the subspecies L. scutellare basoglabrose had no significant differences from the original L. scutellare [1]. The techniques of esterase isoenzymes were thought to be an auxiliary method to identify some close species and subspecies of mites [15,16]. Sun and Wang (1988) used polyacrylamide gel electrophoresis (PAGE) to study the esterase isozymes of 5 species of chigger mites, L. deliense, L. rubellum, $L$. scutellare, L. pallidum, and Odontacarus majesticus. Of the 5 mite species, 4 species (L. deliense, L. rubellum, L. scutellare, and $L$. pallidum) belong to the same genus (Leptotrombidium), subfamily (Trombiculinae), and family (Trombiculidae). The mite
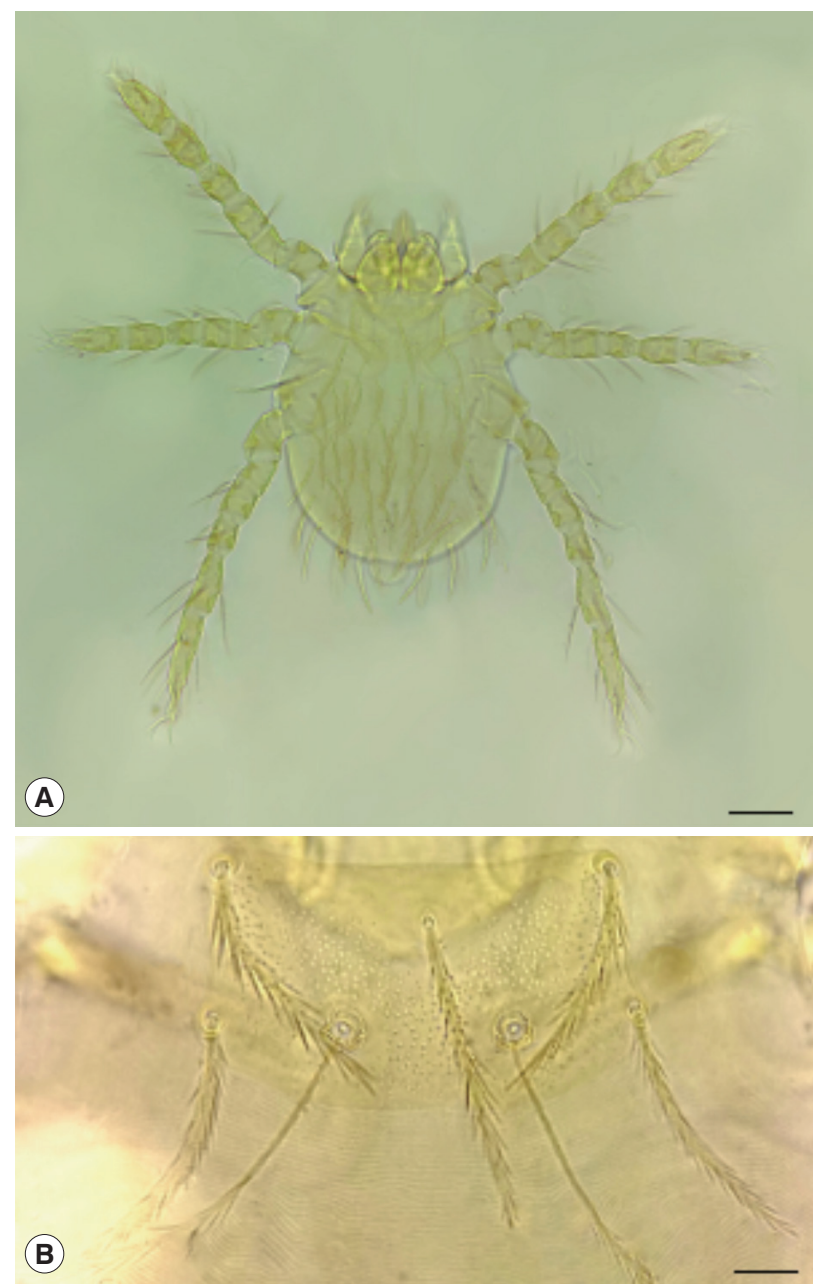

Fig. 1. Leptotrombidium scutellare. (A) Larva. Scale bar $=50 \mu \mathrm{m}$. (B) Scutum. Scale bar $=10 \mu \mathrm{m}$.

Table 1. The key points for the identification of six main vector species of chigger mites in China $[1,2,8,9]$

\begin{tabular}{|c|c|c|c|c|}
\hline Species of chigger mites & PLs and SB & AP and SB ( $\mu \mathrm{m})$ & $\mathrm{PL}, \mathrm{AM}$, and $\mathrm{AL}$ & fDS \\
\hline L. deliense & SB/PLs & AP $(24-30)<$ SB (26-31) & $\mathrm{PL}>\mathrm{AM}>\mathrm{AL}$ & $2 \mathrm{H}-8-6-6-4-2$ \\
\hline L. scutellare & SB \| PLs & AP (28-29)<SB (30-32) & $\mathrm{PL}>\mathrm{AM}>\mathrm{AL}$ & $2 \mathrm{H}-10-[10-2]-[12-4]-8-6-2$ \\
\hline L. rubellum & SB/PLs & AP (29-33) > SB (22-24) & $\mathrm{PL}>\mathrm{AM}>\mathrm{AL}$ & $2 \mathrm{H}-8-6-6-4-2$ \\
\hline L. sialkotense & SB/PLS & AP (24-30)< SB (25-33) & $\mathrm{AM} \geq \mathrm{PL}>\mathrm{AL}$ & $2 \mathrm{H}-8-6-6-6-4$ or $2 \mathrm{H}-8-6-8-6-2$ \\
\hline L. wenense & PLs/SB & AP (12-15)< SB (20-24) & $P L \gg A L>A M$ & $2 \mathrm{H}-8-6-6-4-2-2$ \\
\hline L. insulare & PLs/SB & AP (21-26) < SB (28-32) & $\mathrm{PL}>\mathrm{AM}>\mathrm{AL}$ & $2 \mathrm{H}-10-2-8-10-6-4-2$ \\
\hline
\end{tabular}

PLs: The line between posterolateral setae of scutum; ll: The same horizontal line; /: Above or below the horizontal line. 
species O. majesticus, however, belongs to the different genus (Odontacarus), subfamily (Leeuwenhoekiinae), and family (Leeuwenhoekiidae). In the isozyme spectrum, L. scutellare showed a high similarity to $L$. deliense and $L$. rubellum, a little difference from $L$. pallidum, but very different from $O$. majesticus. The isozyme spectrum supported the hypothesis that $L$. scutellare, $L$. deliense and $L$. rubellum were in the same species group $[1,16]$. The study of chromosomes revealed that $L$. scutellare had the same chromosomal karyotype $(2 n=16)$ with $L$. pallidum $(2 \mathrm{n}=16)$, but different from $L$. deliense $(2 \mathrm{n}=14)$, and O. majesticus $(2 \mathrm{n}=14)[2,17]$. Although $L$. scutellare and $L$. pallidum had the same karyotype $(2 \mathrm{n}=16)$, the G-band and Cband of their chromosomes are significantly different, and this reflected the interspecific difference between $L$. scutellare and $L$. pallidum [18].

\section{GROWTH AND DEVELOPMENT}

Like all the species of chigger mites, Leptotrombidium scutellare has 7 basic stages in its life cycle, including the egg, deutovum (or prelarva), larva, protonymph (or nymphochrysalis), deutonymph (or nymph), tritonymph (or imagochrysalis) and adult (male and female) $[19,20]$. The temperature and humidity were considered 2 important factors affecting the growth and development of $L$. scutellare. Under the laboratory condition of about $25-30^{\circ} \mathrm{C}, 100 \%$ relative humidity and adequate food supply, L. scutellare took 114-172 days (average 145.13 days) to develop into the adult from the larva. It took 34-163 days (average 101.96 days) to develop into the nymph form the larva. The nymphochrysalis and imagochrysalis stages were 32-98 days (average 65.83 days) and 32-83 days (average 49.35 days) respectively. The duration of a complete life cycle was about 9-12 months [19]. Under the condition of room temperature, the development of L. scutellare needed about 5 months from the larva to the adult. In an incubator at $28^{\circ} \mathrm{C}$, the life cycle of $L$. scutellare obviously shortened with the increase of survival rate, and the period from the larva to the adult was only 4 months $[19,20]$. An investigation from Fuzhou in Fujian Province showed that the oviposition peak usually occurred in late October and afterward [19]. The eggs of the flea Xexnopsylla cheopis was used to feed $L$. scutellare at $26^{\circ} \mathrm{C}$ of laboratory condition, and a nymph's consumption was 0.3-0.5 flea eggs/per day (the maximum 2 flea eggs/per day) and an adult's consumption was 2.33 flea eggs/per day $[19,20]$. In the natural environment, $L$. scutellare generally went through one generation, for it took about 9-12 months from the first generation of larvae to the second generation of larvae $[19,20]$.

To scientists' surprise, Leptotrombidium scutellare had strong survivability in water [21]. Yang (1992) observed that the larvae of $L$. scutellare had certain adaptability in water and they could survive for a long time (4-32 days) in water ( $\mathrm{PH}=7.3)$, and this may probably help the mites to spread in the rainy seasons [21].

\section{MATING BEHAVIOR AND OVIPOSITION}

A study showed that the male Leptotrombidium scutellare began to produce spermatophores within 10-55 days (average 38.40 days) after emerging from an imagochrysalis [19]. A spermatophore is composed of a sperm ball and sperm filament. A sperm ball is supported by a sperm filament and it contains semen and sperms (spermatozoa). When a female $L$. scutellare encounters the sperm ball with sperms (spermatozoa), the female crawls over the sperm ball and takes the sperm ball with its palps into its genital pore to finish the indirect mating or indirect fertilization $[1,2]$. The pregnant female L. scutellare began to lay its eggs in the topsoil 45-84 days after emerging from an imagochrysalis. No parthenogenesis was reported in L. scutellare [19].

\section{HOST SEEKING BEHAVIOR}

The larvae of Leptotrombidium scutellare were not active at night with small numbers [1]. The temperature, sound, vibration, sweat, salivary and some other chemicals from the hosts could stimulate the activity of the mite larvae $[1,22]$. When the environmental temperature was above $10^{\circ} \mathrm{C}$, the larvae of $s \mathrm{Cu}$ tellare began their crawling activity. At $28^{\circ} \mathrm{C}$ of laboratory condition, the larvae of scutellare crawled at a speed of $10 \mathrm{~cm} / \mathrm{per}$ min [22]. Scientists found that the attachment of L. scutellare larvae to its hosts could be an active behavior. The larvae could crawl onto some short plants to wait for suitable hosts. The larvae of L. scutellare larvae could crawl onto some plants at the height of $20-29 \mathrm{~cm}$. The larvae were highly clustered on the top of the vegetation when they were waiting for their hosts and this would help them successfully to crawl onto the hosts [23]. 


\section{PARASITISM ON THE HOST}

It was observed that the larvae of Leptotrombidium scutellare fed on the lymph, body fluid and decomposed tissue of their hosts through the sucking activity, and their most common hosts were rodents and some other small mammals $[1,24]$. The L. scutellare larvae were usually concentrated on the auricle (ear shell), ear lobe and external auditory canal of their rodent hosts. Occasionally a large number of $L$. scutellare larvae could be found on some other places of rodents, such as chest, axillary region, inguinal regions and perianal regions $[1,19]$. The common attachment sites of L. scutellare larvae on human body were some soft, thin and hidden parts of the skin, for example, axillary region (armpit), inguinal regions (groin), popliteal fossa, folded joint and the skin under the underwear $[1,25]$. The stylostome was usually formed $3 \mathrm{hr}$ after the attachment of the larvae, but the major feeding activity occurred mainly in the early $48 \mathrm{hr}$, which would lead to a prominent pathological lesion [25]. The L. scutellare mites often showed an aggregated distribution pattern among different individuals of their rodent hosts, which revealed the fact that some hosts harbored many mites (forming clumps of the mites), but some other hosts had few or even no mites on their body surface. The aggregated distribution pattern reflected the intraspecific cooperation of the mites and it would be beneficial to the survival, mating and reproduction of the mites [26-28].

\section{DISTRIBUTION, HOST SELECTION AND ECOLOGY}

In China, Leptotrombidium scutellare was studied early in the 1850s and it was proved to be the dominant species of chigger mite and the most important vector of scrub typhus in Shandong and Jiangsu [29]. It was originally believed that $L$. scutellare was mainly confined to some regions north in Yangtze River, but afterwards it was found to be a very common species of chigger mites, widely distributing in many provinces of China. To date, L. scutellare has been found in more than 15 provinces of China, including Shandong, Jiangsu, Zhejiang, Anhui, Shanghai, Fujian, Jiangxi, Henan, Hebei, Inner Mongolia, Shanxi, Guizhou, Sichuan, Guangdong, Guangxi and Yunnan, etc. [1,29]. In Yunnan Province, L. scutellare was widely distributed in the whole province, but mainly in some mountainous areas with high altitude, low temperature and low precipitation. The altitude was the most important factor affecting the geographical distribution of L. scutellare [28].
It is believed that the larvae of chigger mites have a wide range of hosts, including mammals, aves (birds), reptiles, amphibians and even some other arthropods $[1,19,24,28]$. To date, 46 species of host animals of Leptotrombidium scutellare have been recorded with very low host specificity. Small mammals, especially rodents (rats, mice and voles) were the most common hosts of L. scutellare $[1,19,24,28]$. The small mammal hosts of $L$. scutellare recorded in China were showed in Table $2[1,19,24,28]$. The main hosts of $L$. scutellare varied in different geographical regions. In some regions north in the Yangtze River, the main hosts of $L$. scutellare were R. losea, $R$. norvegicus and Apodemus agrarius [1,19]. In southwest of China (e.g., Yunnan province), however, the main hosts of L. scutellare were A. chevrieri and Eothenomys miletus which were the main wild rodents in the mountainous areas with high altitude $[27,28]$.

\section{RELATIONSHIP WITH SCRUB TYPHUS}

Before 1999, the prevalence of scrub typhus was mainly confined to some areas of southern China, south of the Yangtze River $[1,29]$. In recent years, the epidemic areas of scrub typhus have gradually spread to nearly the whole China with a series of new foci discovered. Nowadays the incidence of scrub typhus is still increasing, and the cases of the disease have been recorded in more than 20 provinces across the mainland China [29]. Besides, there have been cases reported in Hong Kong, Taiwan and Macao as well [30,31]. In Fuyang city of Anhui Province, farmers with poor sanitation showed a high incidence of scrub typhus because they had more opportunity to be attacked by chigger mites [32]. In Fei county of Shandong Province, an epidemic area of scrub typhus, children from the rural areas had a high risk of suffering from scrub typhus because of a history of field exposure [19].

Of more than 500 species of chigger mites in China, 6 species have been proved to be the main vectors of scrub typhus, and Leptotrombidium scutellare is one of the 6 main vector species $[1,9]$. Through many years' field investigations and laboratory experiments, L. scutellare has been eventually confirmed as the second major vector of scrub typhus in China, and its medical significance is second only to $L$. deliense, the first major vector of scrub typhus in China [1,2]. Some evidence for $L$. scutellare to transmit scrub typhus is listed as follows. 
Table 2. The small mammal hosts of Leptotrombidium scutellare recorded in China

\begin{tabular}{l|l}
\hline Species of hosts & Species of hosts \\
\hline Order Rodentia & Family Rhizomyidae \\
Family Muridae & Rhizomys sinensis \\
$\begin{array}{l}\text { Rattus tanezumi; R. losea; R. nitidus; R. norvegicus; R. brunneusculus } \\
\text { Niviventer andersoni; N.confucianus; N. fulvescens }\end{array}$ & Order Erinaceomorpha \\
Apodemus agrarius; A. chevrieri; A. sylvaticus; A. peninsulae; A. draco & Family Erinaceidae \\
Berylmys bowersi & Neotetracus sinensis \\
Micromys minutus & Hylomys suillus \\
Mus musculis; M.caroli; M. pahari & Order Soricomorpha \\
Bandicota indica & Family Soricdae \\
Leopoldamys edwardsi & Suncus murinus \\
Family Cricetida & Crocidura attenuata; C. dracula; C. lasiura; C. shantungensis \\
Eothenomys melanogaster; E. miletus; E. eleusis; E. proditor; E. custos & Anourosorex squamipes \\
Tscherskia triton & Family Tupaiida \\
Myodes rufocanus & Tupaia belangeri \\
Family Sciuridae & Order Lagomorpha \\
Callosciurus erythraeus & Family Ochotonidae \\
Tamiops swinhoei & Ochotona thibetana; O. hyperborea \\
Dremomys pernyi; D. rufigenis & Order Carinivora \\
Scirotamias forresti & Family Mustelidea \\
Family Petauristidae & Mustela sibirica \\
Petaurista xanthotis & \\
\hline
\end{tabular}

\section{EVIDENCE OF NATURAL INFECTION}

Chinese scientists successfully isolated the agent of scrub typhus, O. tsutsugamushi, from Leptotrombidium scutellare in a series of foci in Jiangsu, Shandong, Heibei, Shaanxi, Fujian $[9,10,33]$.

\section{EVIDENCE OF EXPERIMENTAL TRANSMISSION}

To confirm an effective vector of scrub typhus, all the transmission experiments should be done and repeated in the laboratory, including transovarial transmission $[1,2,9,10]$. The larvae of chigger mites sting and suck their hosts only once in their lifetime and the larvae seldom sting and suck their hosts for the second time. When the first generation of the larvae sucks and obtains the pathogen of scrub typhus (O. tsutsugamushi), the pathogen must be transferred to the second generation of the larvae through the transovarial transmission, otherwise, it would be impossible for the pathogen to be spread from one host to another. Therefore, the transovarial transmission is a very important evidence to confirm an effective vector of scrub typhus $[9,10,34]$. Previous studies showed that Leptotrombidium scutellare larvae could invade and sting human, and the pathogen (O. tsutsugamushi) could be passed from the female mites to their offspring (the next generation) through their egg production $[10,34]$. The unfed larvae of $L$. scutellare collected from the foci of scrub typhus were transferred to the body surface of healthy experimental mice to sting the mice in the laboratory, and the healthy mice eventually got the infection of O. tsutsugamushi. The experiment proved that the pathogen $O$. tsutsugamushi could be transferred from the first generation of $L$. scutellare to its second generation through the transovarial transmission, and L. scutellare could be an effective vector of scrub typhus [34]. L. scutellare mites collected from the natural foci of scrub typhus were made into the injectable suspension in the laboratory and then the suspension was inoculated into the experimental mice. After 2 generations of blind transmission, 2 groups of mice were found to have a positive anti-O. tsutsugamushi antibody in serum [10,33]. Some scientists observed that male L. scutellare mites (adult mites) inoculated with $O$. tsutsugamushi could pass the pathogen to the female mites through transorchial transmission (transspermatophoral transmission), and a large number of $O$. tsutsugamushi agents was then found in the reproductive system (mainly ovary and uterus) of female L. scutellare mites [35].

\section{EPIDEMIOLOGICAL EVIDENCE}

An effective vector of scrub typhus should be the dominant 
species with abundant individuals in an epidemic focus, and its distribution areas and seasonal fluctuation should be consistent with the occurrence of the disease $[1,2,9,10]$. In some foci of scrub typhus in China, Leptotrombidium scutellare was proved to be the dominant species of chigger mites in the local regions and its seasonal fluctuation is highly consistent with the occurrence of scrub typhus. For example, in an epidemic focus of Jiangsu Province, L. scutellare was found to be the most dominant species of chigger mite, accounting for $64.3 \%$ of the total chigger mites in the focus. It began to appear in September, reached a peak in October, and gradually disappeared in late December. Its seasonal fluctuation was consistent with the seasonal distribution of scrub typhus in residents [33]. In many epidemic foci of scrub typhus in Shandong, Tianjin and Heibei, L. scutellare was also the dominant species of chigger mite, and its seasonal fluctuation was consistent with the occurrence of the disease $[9,19,33]$.

\section{RELATIONSHIP WITH HFRS}

HFRS is the abbreviation of hemorrhagic fever with renal syndrome, which is also called epidemic hemorrhagic fever (EHF) in China [11,13]. China has a high incidence of HFRS with more than $90 \%$ of total HFRS cases of the world [11,12]. There are a variety of transmission ways for HFRS, including digestive, respiratory and direct contact transmission, etc. $[13,36]$. In recent years, Chinese scientists have demonstrated that some species of ectoparasitic mites, including some gamasid mites and chigger mites, are probably associated the transmission of HFRS [11,37]. Based on some evidence, the chigger mite Leptotrombidium scutellare was suspected to be the potential vector of HFRS $[1,10,11,34,37]$. The limited evidence, however, is still not very sufficient and more research may be needed. Some evidence on the relationship between L. scutellare and HFRS is listed as follows.

\section{EVIDENCE OF NATURAL INFECTION AND EXPERIMENTAL TRANSMISSION OF HFRS}

Back in the early 21st century, Chinese scholars successively isolated the hantavirus (HV), the pathogen of HFRS, from Leptotrombidium scutellare, and found that the artificial infection, stinging transmission and transovarial transmission could be done and repeated in the laboratory $[10,11,34]$. After that, some scholars used some immunological methods and the techniques of molecular biology to study the relationship between L. scutellare and HFRS. The RNA of hantavirus (HV) was repeatedly detected from L. scutellare by RT-PCR and nested RT-PCR [37]. The structural proteins of the virus were detected from the epithelial cells and ovarian tissue of $L$. scutellare by in situ RT-PCR [38].

\section{EPIDEMIOLOGICAL EVIDENCE OF HFRS}

The field investigation from Jiangsu, Shaanxi and Shandong showed that Leptotrombidium scutellare was the dominant species of chigger mite on the body surface of wild rodents, and its seasonal fluctuation was consistent with the incidence curve of HFRS, mainly in October and November [10,11]. In Jiangsu and Shandong provinces, scientists found that the pathogens of HFRS and scrub typhus were often detected from the same rodent hosts and same mite vectors in the same areas and same seasons simultaneously [19].

\section{CHROMOSOME STUDIES AND SOME OTHER ADVANCES}

All the 8 pairs of chromosomes of L. scutellare were short rod-shaped. From pair 1 to pair 8 , the size of chromosomes gradually became smaller and shorter. Most chromosomes were metacentric or sub-metacentric types, but the centromeres were not obvious. Some scholars speculated that XX-XY type might be the sex determination mechanism of $L$. scutellare, that is, XX for females and XY for males [17].

A new rickettsia was detected from Leptotrombidium scutellare in Qingdao of Shandong province, and it was named Candidatus Rickettsia leptotrombidium [38]. Besides the rickettsia, a lot of symbiotic bacteria were also found in L. scutellare [39,40].

\section{ACKNOWLEDGMENTS}

The present paper is a part of the project supported by the $\mathrm{Na}-$ tional Natural Science Foundation of China (No. 81960380, $81672055)$ to Xian-Guo Guo. We would like to express our sincere thanks to the National Natural Science Foundation of China (No. 81960380, 81672055) and the help from the Innovation Team of Vector Biology, Dali University (No. ZKLX2019104). 


\section{CONFLICT OF INTEREST}

The authors declare there is no conflict interest.

\section{REFERENCES}

1. Li JC, Wang DQ, Chen XB. Trombiculid Mites of China: Studies on Vector and Pathogen of Tsutsugamushi Disease. Guangzhou, China. Guangdong Science and Technology Publishing. 1997, pp 1-570 (in Chinese).

2. Lv Y, Guo XG, Jin DC. Research progress on Leptotrombidium deliense. Korean J Parasitol 2018; 56: 313-324. http://doi.org/10.3347/ kjp.2018.56.4.313

3. Surhone LM, Timpledon MT, Marseken SF. Trombiculidae. Beau Bassin, Mauritius. Betascript Publishing. 2010, pp 1-112.

4. Elliott I, Pearson I, Dahal P, Thomas NV, Roberts T, Newton PN. Scrub typhus ecology: a systematic review of Orientia in vectors and hosts. Parasit Vectors 2019; 12: 513. http://doi.org/10.1186/ s13071-019-3751-X

5. Jeong YJ, Kim S, Wook YD, Lee JW, Kim KI, Lee SH. Scrub typhus: clinical, pathologic, and imaging findings. Radiographics 2007; 27: 161-172. http://doi.org/10.1007/s10800-007-9432-z

6. Kim DM. Clinical features and diagnosis of scrub typhus. Infect Chemother 2009; 41: 315-322 (in Korean). http://doi.org/10. 3947/ic.2009.41.6.315

7. Ding F, Jiang WL, Guo XG, Fan R, Mao KY, Zhao CF, Zhang ZW, Qian TJ, Yang ZH. A preliminary report on Walchia micropelta in Yunnan Province. Sichuan J Zool 2020; 39: 555-562 (in Chinese). http://doi.org/10.11984/j.issn.1000-7083.20200129

8. Stekolnikov AA. Leptotrombidium (Acari: Trombiculidae) of the world. Zootaxa 2013; 3728: 1-173. http://doi.org/10.11646/zootaxa.3728.1.1

9. Wu GH, Jiang ZK,Wang L, Ding LY, Mao CQ, Ma BY. Accordance and identification of vector chigger mites of tsutsugamushi disease in China. Chin J Hyg Insect Equip 2013; 19: 286-292 (in Chinese). http://doi.org/10.19821/j.1671-2781.2013.04.004

10. Wu G, Zhang Y, Guo H, Jiang K, Zhang J, Gan Y. The role of Leptotrombidium scutellare in the transmission of human diseases. Chin Med J (Engl) 1996; 109: 670-673.

11. Yu XJ, Tesh RB. The role of mites in the transmission and maintenance of Hantaan virus (Hantavirus: Bunyaviridae). J Infect Dis 2014; 210: 1693-1699. https://doi.org/10.1093/infdis/jiu336

12. Liu R, Ma H, Shu J, Zhang Q, Han M, Liu Z, Jin X, Zhang F, Xu X. Vaccines and therapeutics against Hantaviruses. Front Microbiol 2020; 10: 2989. http://doi.org/10.3389/fmicb.2019.02989

13. Mittler E, Dieterle ME, Kleinfelter LM, Slough MM, Chandran K, Jangra RK. Hantavirus entry: Perspectives and recent advances. Adv Virus Res 2019; 104: 185-224. http://doi.org/10.1016/bs. aivir.2019.07.002

14. Nagayo M, Miyagawa Y, Mitamura T, Tamiya T, Tenjin S. Five species of tsutsugamushi (the carries of Japanese river fever) and their relation to the tsutsugamushi disease. Am J Epidemiol 1921; 1:
569-591. http://doi.org/10.1093/oxfordjournals.aje.a118053

15. Goka K, Takafuji A. Identification among seven species of spider mites (Tetranychus) (Acari: Tetranychidae) based on enzyme differentiation detected by electrophoresis. Appl Entomol Zool 1997; 32: 127-134. https://doi.org/10.1303/aez.32.127

16. Sun YM, Wang DQ. Study on esterase isozyme of chigger mites. Acta Entomol Sinica 1988; 31: 401-406 (in Chinese).

17. Wang LL, Wang DQ. Studies on the karyotypes of five chigger mites (Acari: Trombiculidae \& Leewenneokiidae). Acta Entomol Sinica 1988; 2: 171-176 (in Chinese).

18. Ye YB, Wang DQ. Preliminary studies on the chromosomes banding of some chigger mites. Acta Entomol Sinica 1992; 35: 165-170 (in Chinese).

19. Lin SJ, Guo XG. Study on Leptotrombidium scutellare and its relation with human diseases. J Anhui Agri Sci 2012; 40: 188-190 (in Chinese). http://doi.org/10.3969/j.issn.0517-6611.2012.01.073

20. Zhang Y, Guo HB, Wu GH, Jiang KJ, Zhang JJ, Gan YH. Studies on bionomics and life history of Leptotrombidium (L.) scutellare. Chin J Vector Bio Control 1996; 7: 174-176 (in Chinese).

21. Yang GR. Observation on the vitality of Leptorombidium scutellare larvae in water. Chin J Vector Bio Control 1992; 6: 395 (in Chinese).

22. Suzuki T. Studies on the bionomics and chemical control of tsutsugamushi (scrub-typhus mites). II. Trombicula scutellaris Nagayo et al. in southern Kanto of Japan. Jpn J Exp Med 1954; 24: 181197.

23. Tsunoda T, Takahashi M. Host-seeking behavior of trombiculid mites on vegetation in relation to sika deer. J Med Entomol 2015; 52: 283-288. http://doi.org/10.1093/jme/tjv010

24. Peng PY, Guo XG, Ren TG, Done WG, Song WY. An updated distribution and hosts: trombiculid mites (Acari: Trombidiformes) associated with small mammals in Yunnan province, southwest China. Parasitol Res 2016; 115: 1923-1938. http://doi.org/10.1007/s00436016-4934-4

25. Shatrov AB, Takahashi M, Noda S, Misumi H. Stylostome organization in feeding Leptotrombidium larvae (Acariformes: Trombiculidae). Exp Appl Acarol 2014; 64: 33-47. http://doi.org/10.1007/ s10493-014-9809-8

26. Guo XG, Qian TJ, Meng XY, Dong WG, Shi WX, Wu D. Preliminary analysis of chigger communities associated with house rats (Rattus flavipectus) from six counties in Yunnan, China. Syst Appl Acarol 2006; 11: 13-21. http://doi.org/10.11158/saa.11.1.2

27. Peng PY, Guo XG, Song WY, Hou P, Zou YJ, Fan R. Ectoparasitic chigger mites on large oriental vole (Eothenomys miletus) across southwest, China. Parasitol Res 2016; 115: 623-632. http://doi. org/10.1007/s00436-015-4780-9

28. Zhan YZ, Guo XG, Zuo XH, Wang QH, Wu Q. Research on the area distribution and host selection of Leptotrombidium scutellare in 19 counties of Yunnan Province. Chin J Parasitol Parasitic Dis 2011; 29: 393-396 (in Chinese).

29. Li J, Li XY, Liu YX. Epidemiology of scrub typhus and its transmitting vector research progress in China. Pract Prev Med 2005; 12: 1251-1253 (in Chinese). http://doi.org/10.3969/j.issn.1006- 


\subsubsection{3}

30. Ma SK, Wong WC, Leung CW, Lai ST, Lo YC, Wong KH, Chan MC, Que TL, Chow KW, Yuen MC, Lau TW, Simon J. Review of vector-borne diseases in Hong Kong. Travel Med Infect Dis 2011; 9: 95-105. http://doi.org/10.1016/j.tmaid.2010.01.004

31. Kuo CC, Lee PL, Chen CH, Wang HC. Surveillance of potential hosts and vectors of scrub typhus in Taiwan. Parasit Vectors 2015; 8: 611. http://doi.org/10.1186/s13071-015-1221-7

32. Liu XN. Study the Endemical Genotype of Orientia tsutsugamushi and risk factors of autumn-winter scrub typhus in Fuyang city, Anhui Province. Master's Thesis. Hefei, China. Anhui Medical University. 2019 (in Chinese).

33. Jiang ZK, Wu GH, Li BJ, Wang CJ, Han ZJ, Tan WL, Ding LY, Wang L, Ma BY, Mao CQ. General situation of studies on vector chigger mite of tsutsugamushi disease of autumn-winter type in China. Chin J Hyg Insect Equip 2013; 19: 473-477 (in Chinese). http://doi.org/10.19821/j.1671-2781.2013.06.004

34. Wu GH, Zhang Y, Guo HB. Study on transovarian transmission of pathogen in Leptotrombidium scutellare. Chin J Vector Bio Control 2004; 15: 301-303 (in Chinese). https://www.researchgate. net/publication/287737474

35. Li JC, Zheng XY,Xi ZY, Ni H, Zhang HH, Chen CF. Basic studies on trombiculid mites and vector chiggers mites in the transmission of tsutsugamushi disease for 45 years. Acad J Sums 2002; 23: 1-9 (in
Chinese). http://doi.org/10.3321/j.issn:1672-3554.2002.01.001

36. Xiao H, Tong X, Gao LD, Xu SX, Tan H, Huang ZY, Zhang GG, Yang QQ, Li XY, Huang R, Tong SL, TIan HY. Spatial heterogeneity of hemorrhagic fever with renal syndrome is driven by environmental factors and rodent community composition. PLoS Negl Trop Dis 2018; 12: e0006881. http://doi.org/10.1371/journal.pntd.0006881

37. Zhang Y. Research progress on transmission of hantavirus by mites. Chin J Exp Clin Virol 2003; 17: 101-106 (in Chinese).

38. Huang YT, Zhao L, Zhang ZT, Liu MM, Xue ZF, Ma DQ, Sun XF, Sun Y, Zhou CM, Qin XR, Zhu YL, Li WQ, Yu H, Yu XJ. Detection of a novel Rickettsia from Leptotrombidium scutellare mites (Acari: Trombiculidae) from Shandong of China. J Med Entomol 2017; 54: 544-549. http://doi.org/10.1093/jme/tjw234

39. Ogawa M, Takahashi M, Matsutani M, Takada N, Noda S, Saijo M. Obligate intracellular bacteria diversity in unfed Leptotrombidium scutellare larvae highlights novel bacterial endosymbionts of mites. Microbiol Immunol 2020; 64: 1-9. http://doi.org/10.1111/13480421.12745

40. Choi YJ, Lee EM, Park JM, Lee KM, Han SH, Kim JK, Lee SH, Song HJ, Choi MS, Kim IS, Park KH, Jang WJ. Molecular detection of various rickettsiae in mites (acari: trombiculidae) in southern Jeolla Province, Korea. Microbiol Immunol 2007; 51: 307-312. http://doi.org/10.1111/j.1348-0421.2007.tb03912.x 